\title{
Vectors of Evolution of Political Reflection and Politainment
}

\author{
D. B. Kazarinova ${ }^{1}$
}

\begin{tabular}{lr}
\hline 1Department of Comparative Politics, RUDN, 6 Miklukho-Maklaya str., Moscow 117198, Russian Federation \\
\hline DOI: $10.18255 / 2412-6519-2020-2-134-141$ & Research Article \\
Full text in Russian
\end{tabular}

The development of political science in Russia largely reflects global trends. The transition to the methodology of quantitative analysis, the increasing role of large interdisciplinary projects with large transnational research teams, the increase in the number of co-authors, the avalanche of publication activity, and the extreme democratization of scientific life are among them. The principle of publish-or-perish, which dominates the education and scientific policies, provokes an exponential growth of publications and a number of negative effects: "salami publications", "guest authorship" , etc. In response to these effects, the ideas of "slow science" in the West and active public discussion in the Russian scientific environment develop. At the same time, the generation of meanings and narratives takes place in journalism and politainment - a sphere where politics and entertainment interact and intertwine, creating a new reality. At this point, political theory is becoming more and more elitist. At the same time, metaphor as a tool of theoretical knowledge is becoming increasingly important. Today, political knowledge is a system of hierarchically constructed interacting and interrelated metaphorical concepts. In this context, the abilities of metaphor are important: not only to describe reality more or less accurately, but also to model it. There are two ways to reflect on the political: the professional community, in the context of mass education and science, moves towards detailing knowledge about a narrow subject, while broader political contexts are reflected by society and its intellectual and creative elites through the narratives of mass culture expressed in metaphorical language.

Keywords: political science, methodology, mass science, publication activity, publish-or-perrish, politainment, metaphor

INFORMATION ABOUT THE AUTHORS

Kazarinova Darya B. $\mid$ E-mail: kazarinova-db@rudn.ru Candidate of Sciences in Politics, associate Professor of Comparative political science

For citation: Kazarinova D. B. Vectors of Evolution of Political Reflection and Politainment // Social'nye i gumanitarnye znanija. 2020. Vol. 6, No 2. P. 134-141. (in Russ.)

(C) Kazarinova D. B., 2020

This is an open access article under the CC BY-NC-ND license (http://creativecommons.org/licenses/by-nc-nd/4.0/) 


\title{
Векторы эволюции политической рефлексии и политейнмент
}

\author{
Д. Б. Казаринова ${ }^{1}$
}

1РУДН, ул. Миклухо-Маклая, 6, Москва, 117198, Российская Федерация

DOI: 10.18255/2412-6519-2020-2-134-141

удк 327

Научная статья
Полный текст на русском языке

Развитие политической науки в России в значительной мере отражает общемировые тенденции, среди которых наиболее массовыми становятся переход к методологии количественного анализа, увеличение роли больших междисциплинарных проектов с большими транснациональными научными коллективами, увеличение количества соавторов, лавинообразный рост публикационной активности и предельная демократизация научной жизни. Принцип publish-or-perish, доминирующий в управлении образовательной и научной сферой, провоцирует экспоненциальный рост научных публикаций и ряд негативных эффектов: «салями-публикации», «гостевое авторство» и др. В ответ на эти эффекты развиваются идеи «медленной науки» на Западе и активное общественное обсуждение в российской научной среде. При этом генерирование смыслов и нарративов происходит в публицистике и политейменте-сфере, где политика и сфера развлечения взаимодействуют и переплетаются, создавая новую реальность. В этой ситуации политическая теория становится все более элитарным занятием. При этом метафора как инструмент теоретического знания приобретает все большее значение. Сегодня политическое знание - это система иерархически выстроенных взаимодействующих и взаимосвязанных метафорических концептов. В этом контексте важны свойства метафоры: не только более или менее точно описывать реальность, но и моделировать ее. Рефлексия политического идет двумя путями: профессиональное сообщество в условиях массовизации образования и науки движется в сторону детализации знаний об узком предмете, в то время как более широкие политические контексты рефлексируются обществом, его интеллектуальными и творческими элитами через нарративы массовой культуры, выраженные метафорическим языком.

Ключевые слова: политическая наука, методология, массовая наука, публикационная активность, publish-or-perrish, политеймент, метафора

ИНФОРМАЦИЯ ОБ АВТОРАХ

Казаринова Дарья E-mail: kazarinova-db@rudn.ru

Борисовна

Для цитирования: Казаринова Д. Б. Векторы эволюции политической рефлексии и политейнмент // Социальные и гуманитарные знания. 2020. Том 6, № 2. С. 134-141.

(C) Казаринова Д. Б., 2020

Статья открытого доступа под лицензией CC BY-NC-ND (http://creativecommons.org/licenses/by-nc-nd/4.0/) 


\section{Введение}

О состоянии, кризисе или кризисе развития современной политической науки и ее методологии опубликовано немало работ на Западе [1] и в России [2; $3 ; 4]$. Эта проблема находится в фокусе дискуссии отечественных политологов, что нашло отражение в серии круглых столов РАПН совместно с ИНИОН РАН и рядом других крупных научных и образовательных институций, а также ведущих политологических журналов [5; 6]. На общие проблемы мирового развития общественных наук накладываются национальные проблемы отечественной науки и образования (в первую очередь форсированная интернационализация и бюрократизация), которые существенным образом трансформируют политологию как научную и учебную дисциплину.

\section{Методы}

Фактическое схлопывание плюральности гносеологических подходов при нарастающей сложности проявлений политического приводит к тому, что «преобладающей методологией политической рефлексии остается по преимуществу механистическая гносеология: динамичные нелинейные процессы рассматриваются преимущественно в линейно-детерминистском ключе» [2; с. 24]. На практике это выражается в том, что все более распространенным методом изучения политических проблем становится количественный анализ, построение различного рода моделей на основе регрессивного анализа, оценивания методом «разность разностей» (difference-in-differences) (статистический метод, используемый в эконометрике и количественных исследованиях в социальных науках), использования программ обработки естественного языка, других методов с использованием искусственного интеллекта. Такие современные методы, с одной стороны, позволяют с большой точностью обрабатывать данные, в том числе большие данные bigdata. C другой стороны, как подчеркивает Р. Таагепера, использование математических формул еще не делает политологию более научной с точки зрения точности получаемых знаний [1]. Авторы уделяют все большее внимание описанию выборки, конкретных методик расчета и интерпретации данных. В результате методологический редукционизм привел к тому, что «политология, как и другие социальные науки, сегодня менее научна, чем полвека назад» [3]. В исследованиях доминирует фокус на «малых проблемах» [7], и ученые все чаще отдают предпочтение строгости по отношению к актуальности [8].

\section{Результаты}

Дэвид М. Риччи назвал означенный эффект «трагедией политической науки»: поскольку дисциплина стремилась стать более научной для более эффективного решения проблем общества, она стала менее практически актуальной [9].

Следующей проблемой развития социальных наук стало стремление максимизировать количество публикаций. Для академической публикации появилось понятие Least/ smallest/ minimum publishable unit, или Publon - это наименьший объем публикации, минимально необходимый и достаточный объем информации, который можно использовать для подготовки публикации в журнале или тезисах конференции, выступает как часть стратегии максимизации количества публикаций для развития академической карьеры. 
Причины этого видятся в довлеющем над всем международным научным сообществом (правда, в разной степени) принципе «publish or perish» (публикуйся или погибни) - это аллитеративный афоризм, описывающий необходимость публикации академической работы для того, чтобы добиться успеха в академической карьере, сформулированный социологом Л. Уилсоном [10]. Этот принцип побуждает публиковать как можно больше научных статей всех без исключения участников образовательного процесса. В отличие от традиционно принятого в науке представления сообществу целостных обобщенных результатов исследования, в «салямипубликации» данные, собранные одним исследовательским проектом, сообщаются отдельно, полностью или частично в нескольких конечных публикациях.

\section{Эффекты принципа «publish or perish»}

Чтобы ориентироваться во все более разрастающейся совокупности научных текстов, в помощь ученым работает целая индустрия социальных научных сетей и наукометрических баз данных: идентификатор авторов-ученых ORCID, программа для управления библиографической информацией Mendeley, научные социальные сети ResearchGate и Academia.edu, сервис для отслеживания, проверки и рецензирования научных публикаций Publons, поисковая система по научным публикациям GoogleScholar и др. Миссия такого рода сервисов и социальных сетей состоит в том, чтобы «ускорить» науку, как можно быстрее довести «научный продукт» до «конечного потребителя».

Идея о том, что наука страдает от «ускорения» в результате «публикационного давления», неоднократно высказывалась ведущими учеными. Как ответ на эти процессы возникает идея «медленной науки» (Slow, Unhastening science), которая является частью более широкого «Медленного движения (Slow movement)» - культуры замедления ритма жизни. Идея «медленной науки» основана на убеждении, что наука должна быть медленным, устойчивым, методичным процессом и что от ученых не следует ожидать быстрого решения проблем общества. Медленная наука поддерживает научные исследования, ориентированные на поиск научной истины, и отвергает научную производительность в качестве цели. Российское академическое сообщество также последовательно выступает против подобных механизмов управления образованием и наукой, что, в частности, вылилось в кампанию институтов РАН против применения методики расчета «комплексного балла публикационной результативности» Минобрнауки РФ.

Требование к постоянному наращиванию публикационной активности всех участников образовательного процесса (студентов, аспирантов, преподавательского состава, в том числе кафедр иностранных языков, информационных технологий и иных «сервисных» направлений) вместе с повсеместной массовизацией высшего образования и необходимостью его кадрового обеспечения производит эффект, который можно назвать «массовой наукой», несмотря на то, что это словосочетание и кажется оксюмороном. Подчеркнем, что под «массовой наукой» в данном случае понимается отнюдь не наука, идущая в массы (о ней будет сказано позже), а массы, идущие в науку, причем не по доброй воле, а для сохранения себя в профессии. Если взглянуть на требования по критериям и целевым показателям публикационной активности в НИУ ВШЭ, МГУ им. М. В. Ломоносова, МГИМО, МИД РФ, РУДН и других вузах России и сопоставить их с текущим состоянием публикационной активности их преподавателей по базе РИНЦ, можно оценить потенциал роста количества публикаций в ближайшие годы. Динамика роста публикационной активности вузов России [11] 
и так идет темпами, опережающими общемировые. Ориентация на продвижение в международных рейтингах, критерием которых является в том числе и подушевая публикационная активность и цитируемость их ученых, стимулирует эту публикационную гонку к экспоненциальному развитию. Стабилизация количества публикаций на некоем нормальном уровне в этой логике невозможна. Даже для того, чтобы сохранять место в рейтинге, необходимо постоянно наращивать показатели.

При этом критика принципа «publish or perish» не нова и широко распространена, а последствия его применения в жизни научного сообщества уже налицо и позволяют делать следующие выводы: умножение количества публикаций вместо одной обобщающей и концептуальной; увеличение количества соавторов разного уровня причастности к написанию статьи (co-authors, contributor, guest authors) и другие эффекты.

Эти и другие эффекты использования принципов New Public Management в управлении образованием и наукой, в целом представления о том, что социальные процессы могут управляться аналогично бизнес-процессам с использованием «ключевых показателей эффективности» (KPI) и рейтингования, встречают повсеместную критику. Несмотря на это, в образовании и науке в особенности альтернативы этому подходу на уровне управленческой практики в России сейчас нет: все вузы в статусе «ведущих» и научные организации РАН работают на выполнение количественных показателей. Ввиду этого количество новых научных работ выросло на 5 \% с 1539695 статей (в 2017 г.) до 1620731 статей (в 2018 г.), включенных в базу научных данных Web of Science [12]. Доля России в «валовом научном продукте» тоже постепенно растет, что укрепляет ее позиции в международных рейтингах, но при этом умножает количество не только качественных, но и т. н. «мусорных» публикаций, а тенденции использования описанных управленческих стратегий в образовании и науке заметно укрепляются, что особенно заметно в связи с реализацией Проекта повышения конкурентоспособности российских вузов «5-100» Министерства науки и высшего образования РФ. Соответственно, российскую науку, в том числе политическую, ожидает сходная трансформация.

\section{Нетрадиционные подходы к политическому познанию}

У «массовой науки» может быть два измерения: во-первых, это «массы, идущие в науку», - увеличение количества ученых, постоянно производящих научные тексты; об этой тенденции мы говорили выше. Во-вторых, это, условно говоря, «наука, идущая в массы», черпающая возможности политической рефлексии из ненаучных форм познания, воплощающаяся в том числе в такой гибридный феномен, как политеймент. Как было сказано выше, классические подходы зачастую оказываются нерелевантными, так как они не успевают фиксировать реальность в силу высокой динамики социальных трансформаций. В связи с этим «сегодня так или иначе необходимо решать вопрос о совместимости классических и нетрадиционных подходов к политическим явлениям. Причем важность обретают и собственно когнитивные, и семантические, и семиотические аспекты познания» [13]. Политическая рефлексия обращается к нарративам, медиа и новым формам политической коммуникации.

Политеймент подразумевает «политику как единство новости, рекламы и развлечения» [14], новую реальность эпохи всеобщей медиатизации и постправды, которая описывает тенденции в политике и средствах массовой информации, используя элементы связей с общественностью для создания нового вида политической 
коммуникации. Политеймент предстает и как средство инсценирования политической коммуникации, симбиоз политики и культуры развлечений. Это целая сфера, где политика и сфера развлечения взаимодействуют и переплетаются, создавая новую реальность. Концепт также предполагает понимание современной политики как бизнеса [15]. Термин «политеймент» характеризует одновременно несколько процессов: во-первых, это «политическое развлечение», когда индустрия развлечений эксплуатирует политические темы в различных развлекательных форматах; во-вторых, это «развлекательная политика», когда политические акторы капитализируют свою публичность (выступления в ток-шоу, участие в светских мероприятиях и т. д.) в целях продвижения собственного имиджа и решения определенных вопросов. В широком понимании политеймент выходит за рамки информационно-развлекательной деятельности, используя популярную культуру как потенциальное пространство для политической деятельности, с одной стороны, а с другой - рефлексии о ней, признавая развлекательные форматы в качестве источника политических знаний о ценностных ориентациях и гражданской активности [16]. Такие жанры, как комикс, блокбастер о супергероях, полнометражный мультипликационный фильм, многое говорят о реалиях геополитики и транслируемых ценностях.

\section{Метафора в современной политической науке}

Осмысление политической реальности часто происходит посредством анализа разнообразных явлений политеймента. В «отсутствии на протяжении нескольких десятилетий значимых новационных идей и эвристически эффективных теорий / парадигм [3], способных стать ответом на критические эндогенные и экзогенные политико-интеллектуальные вызовы», общество рефлексирует в новых форматах, а ученые занимаются их вторичным анализом. Научно-публицистическая деятельность также во многих случаях развивается по законам и как часть политеймента. И здесь ключевую роль играет метафора как инструмент концептуализации политической реальности. «Человечество всегда познавало и продолжает познавать мир через инструмент метафоры, сравнивая незнакомое со знакомым» [17]. Сегодня, во времена «конца знакомого мира» [18], «интеррегнума» [19], такого рода познавательный механизм оказывается тем более востребованным, причем не только в общественном дискурсе, но и в фундаментальной науке.

Метафора в политической коммуникативистике как язык политики хорошо изучена [20] и не является здесь предметом нашего анализа. Метафора в собственно политической теории как способ описания политических реалий в политической науке также имеет сильные корни. Начиная с «Левиафана» Т. Гоббса, заканчивая «Концом истории» и «Последним человеком» Ф. Фукуямы, «Мягкой силой» Дж. Ная, история развития политической мысли в значительной степени строится на метафоре. Как показывает филолог Ю. Соловьева, в англоязычном политологическом дискурсе, который лежит в основе современного языка науки политологии, «функционирует система взаимодействующих и взаимосвязанных метафорических концептов, посредством которых репрезентируются основные понятия политологии и ее основные теории ... Метафорические концепты, функционирующие в англоязычном политологическом дискурсе, образуют иерархическую систему, где имеются более простые концептуальные метафоры (контейнер, баланс, структура), посредством которых основные понятия политологии объясняются в учебниках, а также более сложные концептуальные метафоры (строение, механизм, персонификация, путеше- 
ствие), включающие в себя более частные концептуально-метафорические представления» [21]. В политическую теорию метафоры естественным образом проникают из реального политического дискурса: Холодная война, Игра с нулевой суммой, Ловушка Фукидида - вошли в пул понятий, которыми ученые оперируют без пояснений и ссылок как уже устоявшимися. При этом успех теории в академическом сообществе зачастую связан не столько со степенью концептуализации и исчерпывающей операционализацией нового термина, сколько с меткостью и образностью метафоры, которая взята в качестве названия той или иной теории. В том случае, если метафора позволяет верно и глубоко отразить реальность, она приживается и довольно быстро входит в язык науки в качестве устойчивого выражения.

Как подчеркивает филолог М. Штейнман, «важное свойство политической метафоры - способность моделировать ту или иную версию политической реальности» [22]. И это справедливо не только для политики, но и для рефлексии о ней. В ситуации «размывания референтов и референций» [2], когда принятые понятия перестают отражать новые реалии, «последние зачастую можно осмыслить лишь посредством метафоры, которая, в свою очередь, обладает способностью порождать смыслы ... В ситуации высокой неопределенности по-настоящему действенной стратегией выявления проблем способна быть только метафора» [22]. Безусловно, это далеко не единственный алгоритм познания. Метафора, как и политеймент, никоим образом не заменяет классических академических форм политической рефлексии, но активно дополняет их.

\section{Выводы}

Таким образом, рефлексия политического идет двумя путями: профессиональное сообщество в условиях массовизации образования и науки движется в сторону детализации знаний об узком предмете посредством преимущественно количественного анализа, большей научности при определенных потерях в актуальности, в то время как более широкие политические контексты рефлексируются обществом, его интеллектуальными и творческими элитами через нарративы массовой культуры, выраженные метафорическим языком.

\section{Ссылки / References}

1. Таагепера Р. Две моих мечты. Изложение лекции Рейна Таагеперы, лауреата премии имени Карла Дойча // Политическая наука. 2018. № 1.

2. Гаман-Голутвина О.В.Преодолевая методологические различия: споры о познании политики в эпоху неопределенности // Полис. Политические исследования. 2019. № 5.

3. Ильин М. В. Современная политическая наука: кризис или развитие? // Политическая наука. 2018. № 1. С. 40-67.

4. Торкунов А. В. Вызовы социогуманитарной науке в России // Полис. Политические исследования. 2018. № 5. С. 8-16. https://doi.org/10.17976/jpps/2018.05.02

5. Гаман-Голутвина О. В., Сморгунов Л. В., Тимофеева Л. Н. Политическая наука перед вызовами современной политики (VII Всероссийский конгресс политологов, 19-21 ноября 2015 г., Москва, МГИМО МИД РФ) // Политическая наука. 2016. № 2.

6. Современная политическая наука: кризис или развитие? // Политическая наука, 2018. № 1. C. 40-67. 
7. Taagepera R. Science Walks on Two Legs, but Social Sciences Try to Hop on One // International Political Science Review. 2018. Vol. 39. № 1. P. 145-159. https://doi.org/10.1177/0192512116682185

8. Desch M. C. How Political Science Became Irrelevant. The field turned its back on the Beltway, 2019. URL: https://www.chronicle.com/article/How-Political-Science-Became/245777 (дата обращения: 15.11.2019)

9. Ricci D. M. The Tragedy of Political Science. Politics, Scholarship, and Democracy. New Haven: Yale University Press, 1987.

10. Wilson L. The Academic Man: A Study in the Sociology of a Profession. Routledge, 1995.

11. Гришакина Е. Г. Публикационная активность российских исследователей: университетская наука // Наука. Инновации. Образование. 2016. № 4 (22).

12. Pakistan and Egypt had highest rises in research output in 2018. Global production of scientific papers hit an all-time high this year, estimates show, with emerging economies rising fastest. URL: https://www.nature.com/articles/d41586-018-07841-9. doi: 10.1038/d41586-01807841-9 (дата обращения: 15.11.2019)

13. Соловьев А. И. Страничка главного редактора // Политическая рефлексия, теория и методология научных исследований. М., 2017. С. 3.

14. Больц Н. Азбука медиа. М.: Европа, 2011.

15. Schultz D. Politainment: The Ten Rules of Contemporary Politics: A citizens' guide to understanding campaigns and elections, 2012. URL: https://www.mruni.eu/mru_lt_dokumentai/fakultetai/business_and_media_school/politainm ent $\% 20$ rules $\% 20$ of\%20politics $\% 20 \% 20$ final.pdf (дата обращения 20.04.2020)

16. Politainment // The International Encyclopedia of Political Communication. Wiley Online Library, 2016. doi: 10.1002/9781118541555.wbiepc157

17. Коктыш К. Е. Теория метафоры и политические институты / Под ред. Т. А. Алексеевой. М.: МГИМО-Университет, 2019. 226 с.

18. Валлерстайн И. Конец знакомого мира: Социология XXI века / Пер. с англ. под ред. Б. Л. Иноземцева; Центр исследований постиндустриального общества. М.: Логос, 2003.

19. Бауман 3. Междувластие // Россия в глобальной политике. 2012. № 6. URL: https://globalaffairs.ru/number/Mezhduvlastie-15784 (дата обращения: 15.11.2019)

20. Артамонова Ю. Д., Демчук А. Л. Когнитивная теория метафоры в современной российской политологии: Методологические проблемы // Политическая наука. 2017. № 2. С. 16-29.

21. Соловьева Ю. А. Концептуальная метафора в англоязычном научном политологическом дискурсе: автореф. дисс. ... канд. филол. наук. M., 2011. URL: http://cheloveknauka.com/kontseptualnaya-metafora-v-angloyazychnom-nauchnompolitologicheskom-diskurse\#ixzz616EGVD8k (дата обращения: 15.11.2019).

22. Штейнман М. А. Трансформация метафоры власти в XX - начале XXI столетия на примере произведений Дж. Р. Р. Толкина и Дж. Мартина // Полития. 2019. № 2 (93). URL: http://politeia.ru/files/articles/rus/Politeia-2019-2(93)-28-47.pdf (дата обращения: 15.11.2019). doi: 10.30570/2078-5089-2019-93-2-28-47. 